\title{
The framing of climate change discourse by Statoil
}

\author{
Oleksandr Kapranov* \\ Western Norway University of Applied Sciences, Norway
}

\begin{abstract}
This article involves a qualitative framing analysis of climate change discourse by Statoil, a Norwegian-based energy corporation, which is considered to be a major actor in the Norwegian fossil fuels market. The corpus of the present framing analysis consists of Statoil's annual sustainability reports from 2001 until 2015 available online at the official Statoil website www.statoil.com. The framing analysis is based upon the methodological approach to framing described by Dahl (2015). The specific research aim of the present investigation is twofold: i) to identify Statoil's framing of climate change discourse and ii) to compare how the framing changed diachronically from the time of the first sustainability report published in 2001 until the 2015 Sustainability Report. The results of the framing analysis indicate that Statoil's climate change discourse in 2001-2015 is framed by a number of qualitatively different frames that are unequally distributed in diachrony, e.g. "Anthropogenic Cause", "Battle", "Corporate Responsibility", "Emissions Reduction" etc. These frames are further presented and discussed in the article.
\end{abstract}

\section{Key words}

climate change, discourse, frame, framing, Statoil

\section{Introduction}

This article involves a qualitative investigation of how the Norwegian fossil fuels and energy corporation Statoil frames its discourse about climate change. Anthropogenic climate change is a complex environmental problem, which causes ecological disruptions, e.g. storms, floods and droughts (Tynkkynen, 2010, p.179). Since the issue of climate change is complex, it requires multiple actors to provide an adequate climate change mitigation strategy (Berbés-Blázquez et al., 2017, p.1). The effectiveness of climate change mitigation is associated with how the general public as well as corporate actors frame their climate change discourse (Swain, 2017, p.168). Whilst previous research has provided ample ground for elucidating climate change discourse via the lenses of framing (Benjamin, Han-Hui, and Budescu, 2016; Curran, 2017; Nerlich and Jaspal, 2013; Nisbet, 2009; Schmid-Petri and Arlt, 2016; Shehata and Hopmann, 2012; Tynkkynen, 2010), framing analysis has not been applied to climate change discourse by Statoil, a major Norwegian and international fossil fuel corporation. The novelty of the research further described in this article consists of a diachronic framing analysis of climate change discourse in the corporate sustainability reports by Statoil within the period of time from 2001 until 2015. This article is structured as follows: first, background notions involving i) "greenwashing" in relation to climate change, and ii) the Norwegian corporation Statoil in the context of climate change

\footnotetext{
*Address for correspondence: Oleksandr Kapranov, Faculty of Teacher and Cultural Education, Western Norway University of Applied Sciences, postboks 7030, 5020 Bergen, Norway. E-mail: oleksandr.kapranov@uib.no
} 
mitigation will be given. Second, the framing approach to climate change discourse will be outlined. Third, a framing analysis of Statoil's climate change discourse will be presented and discussed.

\subsection{Background notions: (i) 'Greenwashing' in relation to climate change, and (ii) the Norwegian corporation Statoil in the context of climate change mitigation}

Prior to proceeding to the main focus of this article, it seems relevant to provide an outline of Statoil's and other international fossil fuel corporations' attitude towards climate change. Statoil and other fossil fuel corporations are considered to be sensitive to environmental performance, in particular, to the issue of global climate change (Gonenc and Scholtens, 2017). Specifically, corporate sensitivity to climate change has resulted in "greenwashing", understood as corporate claims to address the issue of global climate change to gain financial benefits, whilst no actual changes in corporate operations are undertaken (Gonenc and Scholtens, 2017). Previous research reveals that major fossil fuel corporations tend to present their environmental and climate change-related activities in a positive manner, thus communicating "overly positive beliefs about an organization's environmental performance, practices, or products" (Lyon and Montgomery, 2015, p.3). An example of such a positive framing based upon "greenwashing" is evident from BP's campaign to rebrand its name British Petroleum as Beyond Petroleum (Matejek and Gössling, 2014). This framing is executed by means of discourse narratives about BP's sustainable development and climate change-related activities, thus promoting BP as a corporation with substantial environmental credentials (Doyle, 2007, p.143). BP has framed its discursive strategy by presenting a more environmentally friendly narrative than is justified by its commercial reality (Garcia, 2011), simultaneously investing in fossil fuels rather than in renewable energy, as implied by the slogan Beyond Petroleum (de Vries, Terwell, and Ellemers, 2015, p.16).

Another case of "greenwashing" involves ExxonMobil, a major international fossil fuel corporation, which has been accused of "greenwashing" based on a series of public relations (PR) campaigns presenting the corporation in a favourable light as far as climate change is concerned (Scanlan, 2017). Similarly to ExxonMobil, Europe-based fossil fuel corporations (e.g. BP and Shell) have experienced environmental incidents of significant proportions that negatively impacted upon their image (Kapranov, forthcoming). In particular, BP's corporate image is reported to be negatively affected by the oil spill at the Deepwater Horizon installation (Starbird, et al., 2015).

Previous research (Starbird et al., 2015) indicates that BP's corporate discourse has undergone substantial changes after the spill. Following the Deepwater Horizon spill, BP's discourse emphasizes notions of corporate responsibility in environmental protection and climate change (Kapranov, forthcoming). In contrast with BP, ExxonMobil and Shell, respectively, Statoil has managed to avoid significant negative publicity associated with its environmental and climate change-related activities (Nilsen, 2017). Presumably, Statoil's climate change-related performance is explained by Statoil's strong association with the Norwegian government and the innovative nature of the company:

Since the Norwegian Government established Statoil in 1972, the company has been a major contributor to economic development and growth in Norway. To control and assure that Norwegian oil and gas resources and knowledge were embedded within the Norwegian system, the company has been used as a tool for the Norwegian Government in industrial policy regarding building local content in the industry in Norway. Following Statoil's merger with its Norwegian competitor Hydro in 2007, Statoil became the single dominant company with a Norwegian ownership structure, while other companies operating on the Norwegian continental shelf were either smaller or had foreign ownership. Statoil's position has resulted in the provision of a large stock of new technologies and numerous innovations within Norwegian business. (Nilsen, 2017, p.52)

Given that Statoil is a predominantly state-run corporation, it seems logical to assume that Statoil's climate change-related operations reflect, to an extent, a timeline of climate change negotiations, including the Kyoto Protocol and the Paris Climate Change Agreement (Graham, 2017; Nilsen, 2017). Presumably, the Paris Agreement has had an impact on Statoil's sustainability reports, since Norway signed that agreement and indicated its willingness to address the issue of climate change, especially the problem associated with greenhouse gas emissions (Marshall, 2007). Arguably, the Paris Agreement 
alongside with the Kyoto Protocol provide Statoil with an incentive to support lower-carbon and renewable fuel sources (Graham, 2017). Extending this contention further, it can be argued that Statoil's framing of climate change discourse is reflective of the Norwegian government's involvement into an international endeavour of climate change mitigation. The way Statoil frames its climate change discourse will be addressed in the following subsections of this article.

\subsection{An outline of the framing approach to climate change discourse}

As indicated by Cornelissen and colleagues (2011, p.1701), "frame" and "framing" have been used over the years in various fields. Framing is a linguistic, psychological and sociological concept, which is concerned with the construction of meaning (Cranmer, Bowman, and Goldman, 2017; Curran, 2017; Dahl, 2017; De Vries, Terwell, and Ellemers, 2015; Garcia, 2011). Goffman (1974, p.21) posits that framing is a schema of interpretation that enables individuals to locate, perceive, identify and label life experiences. Similarly to Goffman (1974), framing is deemed to underlie the process of sense making in order to give structure and meaning to the world (Entman, 1993).

Framing involves a process of construing a particular conceptualization of a certain experience or an issue (Chong and Druckman, 2007, p.104). Consequently, frames are comprised of the selection of some aspects of an experience or an issue that make them more salient in a communicative context (Entman, 1993, p.52). Echoing Entman (1993), it is suggested that framing involves the foregrounding of specific problem definitions, causal interpretations, moral evaluations and treatment recommendations for an issue by selecting certain aspects while backgrounding others (Curran, 2017; Levin, Schneider, and Gaeth, 1998; Matthes and Kohring, 2008, p.258-260; Schmid-Petri and Arlt, 2016, p.265). To emphasize the concept of framing, it seems pertinent to reiterate that

a frame first of all specifies the relationship between a number of connected and salient elements in a communicated message (i.e. a picture frame) ... This frame, in turn, is anchored in culturally shared, cognitive categories of understanding that guide and ground interpretation. (Cornelissen, Holt, and Zundel, 2011, p.1704)

Frames refer to those specific organizing principles that are socially shared, relatively stable over time, and symbolically meaningful (Levin, Schneider, and Gaeth, 1998; Shehata and Hopmann, 2012). Frames are embedded within social consciousness (Benford and Snow, 2000, p.614; Gebara, et al., 2017). Frames "translate" an uncertain and controversial issue into a clearly identifiable problem that implies a course of action (Entman, 1993; Tynkkynen, 2010). For instance, in mass media discourse, frames are embodied in key words, images and concepts emphasized in stories. Apart from the visual iconic means of framing, rhetorical tools, e.g. metaphors, synecdoche, parabole, analogy, etc., are deemed to construe a frame to make the issue clear to the public, to streamline the narrative context, and to suggest a possible approach to solve the issue (Spence and Pidgeon, 2010; Swain, 2017; Trenberth, 2012).

Initially, the problem of climate change was framed as a scientific issue, and after 1988, as a political one (Jaspal and Nerlich, 2014; Myers et al., 2012). Currently, however, climate change discourse is framed by means of referring to other relevant dimensions, for instance, public health, national security, extreme weather events and the economy (Nisbet, 2009). Previous research indicates that the difference in dimensions involved in the framing of climate change discourse is "due to the many actors and stakeholders with different interests and engagement in the issue' (Fløttum and Gjerstad, 2017, p.2).

The framing of climate change discourse by corporate actors offers an additional facet of this issue (Hurlstone, et al., 2017, p.120). In particular, previous research indicates that the corporate world frames its climate change discourse via the lenses of corporate image management, conceptual metaphors of responsibility, care and citizenship, construals of crisis and risk management (Kapranov, 2016, p.217; Kropp and Turk, 2017). Recent literature in environmental and organization studies suggests that major fossil fuel corporations frame their climate change discourse by communicating positive beliefs about their environmental performance and practices (Lyon and Montgomery, 2015, p. 3). For instance, British Petroleum (BP) frames its climate change discourse by presenting an environmentally friendly narrative (de Vries, Terwell, and Ellemers, 2015, p.16). It has been found that BP and, in particular, Royal Dutch Shell, frame their climate change discourse by means of conceptual metaphors associated with social 
responsibility and environmental awareness (Kapranov, 2015). Specifically, BP's climate change discourse appears to be framed by the issues of environmental sustainability, community investment and the corporation's efforts to mitigate greenhouse emissions (Kapranov, forthcoming). The framing of BP's and Shell's climate change discourse is aimed at construing a positive and socially responsible corporate image.

Previous research suggests that BP and Shell, for instance, employ the framing strategy of their climate change discourse to facilitate comprehension and communication of the issue (Kapranov, 2017; Livesey, 2002). Specifically, it has been found that both BP and Shell make their climate change communication with the general public and the stakeholders comprehensible and more understandable by means of framing it via conceptual metaphors, such as "Corporate Response to Climate Change as a Journey" and "Corporation as a Climate Change Concerned Citizen" (Kapranov, forthcoming). In particular, previous research (Kapranov, 2015) indicates that conceptual metaphor "Corporate Response to Climate Change as a Journey" is present in the annual reports of both BP and Shell. Generally, conceptual metaphors involving the domain Journey are referred to as quantitatively productive in business discourse (Lopez Maestre, 2000). Kapranov (2015) indicates that there are consistent mappings of conceptual elements from the domain Corporate Response to Climate Change onto the domain Journey, identified in BP's and Shell's annual reports from 2010 till 2014. In this mapping, one domain is structured in terms of another by means of the Source-Path-Goal schema (Lakoff, 2006). Climate change (Source) requires corporate measures to reduce and mitigate it (Goal), however these concrete measures unfold in time and eventuate as a gradual process or a planned activity (Path). In the climate change narratives of both BP and Shell, corporate measures to address climate change are understood as a long-term purposeful activity that takes place in space and time and like any other journey has clearly defined starting and finishing points (Kapranov, forthcoming). It should be noted that whilst the framing of climate change by BP and Shell, respectively, appears to be amply elucidated, there are no previous studies involving the framing of climate change discourse by Statoil, one of the major actors on the global fossil fuels market.

\section{The present study, its hypothesis and the main research aim}

Following previous research findings (Nisbet, 2009), the Hypothesis is based upon an assumption that Statoil's framing of climate change is dynamically adjusted to the particular context of the sustainability reports, hence resulting in a dynamic framing of the issue of climate change by Statoil. The Hypothesis is formulated as follows: it is assumed that Statoil's framing of the issue of climate change is characterized by frames, which are unequally distributed in diachrony. Following the Hypothesis, the main research aim of the present qualitative study is formulated twofold: i) to identify Statoil's framing of climate change and ii) to compare how the framing changed diachronically from the time of the first sustainability report published in 2001 until the 2015 Sustainability Report.

\subsection{Materials}

The materials of this study involve Statoil's sustainability reports, available for download at the official website www.statoil.com. At the time of writing this article, in February 2017, the official webpage contained 15 sustainability reports in Pdf format, from 2001 until 2015. No 2016 sustainability report was available at that point. All the sustainability reports are written in the English language. The reports vary in length, with the issue of climate change being allocated either several pages or none at all, as, for instance, in the 2008 Sustainability Report. Typically, the issue of climate change is given a subsection status subsumed under another more encompassing topic, for example "Environmental Performance" or "The Environment". Only in some sustainability reports is the issue of climate change presented in a separate section of the report, e.g. in the sustainability reports published in 2007, 2009, 2013, 2014 and in 2015. A summary of the descriptive statistics of the materials is provided in Table 1 below. 
Table 1. Descriptive statistics of the corpus

\begin{tabular}{llll}
\hline Year & Climate Change Section & Pages & N Words \\
2001 & A part of "Affecting the World around Us" & $55-57$ & 999 \\
2002 & A part of "Environmental Performance" & $20-23$ & 1578 \\
2003 & A part of "The Environment" & $18-21$ & 1496 \\
2004 & A part of "The Environment" & $33-34$ & 1085 \\
2005 & A part of "The Environment" & $42-43$ & 1164 \\
2006 & A part of "The Environment" & $30-33$ & 2470 \\
2007 & A separate section of the 2007 Sustainability Report & $26-27$ & 429 \\
2008 & No separate section/subsection & -- & -- \\
2009 & A separate section of the 2007 Sustainability Report & $3-4$ & 1780 \\
2010 & A part of "Health, Safety, Climate and Environment" & $79-80$ & 1070 \\
2011 & A part of "Climate and Environment" & $49-50$ & 850 \\
2012 & A part of "Sustainability" & $8,33-38$ & 2579 \\
2013 & A separate section of the 2013 Sustainability Report & $8-14$ & 3675 \\
2014 & A separate section of the 2014 Sustainability Report & $9-16$ & 4950 \\
2015 & A separate section of the 2015 Sustainability Report & $9-22$ & 8100 \\
\hline
\end{tabular}

\subsection{Methods}

The methodology used in this article follows the guidelines proposed by Dahl (2015). According to Dahl (2015), text linguistics offers a systematic approach to addressing the question of how frames are manifested in a text. The qualitative methodology of framing analysis by Dahl (2015) is based upon linguistic principles associated with the macro level, e.g. text structure and genre, as well as with the micro level, represented by sentence and word. The methodology proposed by Dahl (2015) involves the following steps i) an examination of a particular text for the presence of key words, recurrent phrases, stereotyped expressions, and sentences that provide thematically reinforcing clustering; ii) an examination of a framework of appraisal resources related to attitudes, feelings and values, used to construe attitude (involving emotions, judgment and appreciation), engagement (relating to the writer's stance towards value positions), and gradability in terms of force (high/low intensity). The abovementioned methodological approach proposed by Dahl (2015) was applied to a corpus of sustainability reports by Statoil. The coding is done by the author of this article.

\subsection{Results and discussion}

The results of the framing analysis reveal that the framing of climate change by Statoil involves a number of heterogeneous frames, which are not equally distributed in diachrony. These frames are summarized in Table 2 below.

Table 2. The framing of climate change in Statoil's sustainability reports 2001-2015

\begin{tabular}{lll}
\hline $\mathbf{N}$ & Year & $\begin{array}{l}\text { Frame } \\
1\end{array} 2001$ \\
& & $\begin{array}{l}\text { "Anthropogenic Cause" } \\
\text { "Battle" } \\
\text { "Emissions Reduction" } \\
\text { "Natural Gas" } \\
\text { "Nmissions Reduction" } \\
\text { "Emissions Trading" } \\
\text { "International Collaboration" }\end{array}$ \\
3 & $2003 \quad \begin{array}{l}\text { "Anthropogenic Cause" } \\
\text { "Emissions Reduction" } \\
\text { "Emissions Trading" } \\
\text { "Renewable Energy" }\end{array}$ \\
4 & $2004 \begin{array}{l}\text { "Anthropogenic Cause" } \\
\text { "Emissions Reduction" } \\
\text { "Emissions Trading" }\end{array}$
\end{tabular}




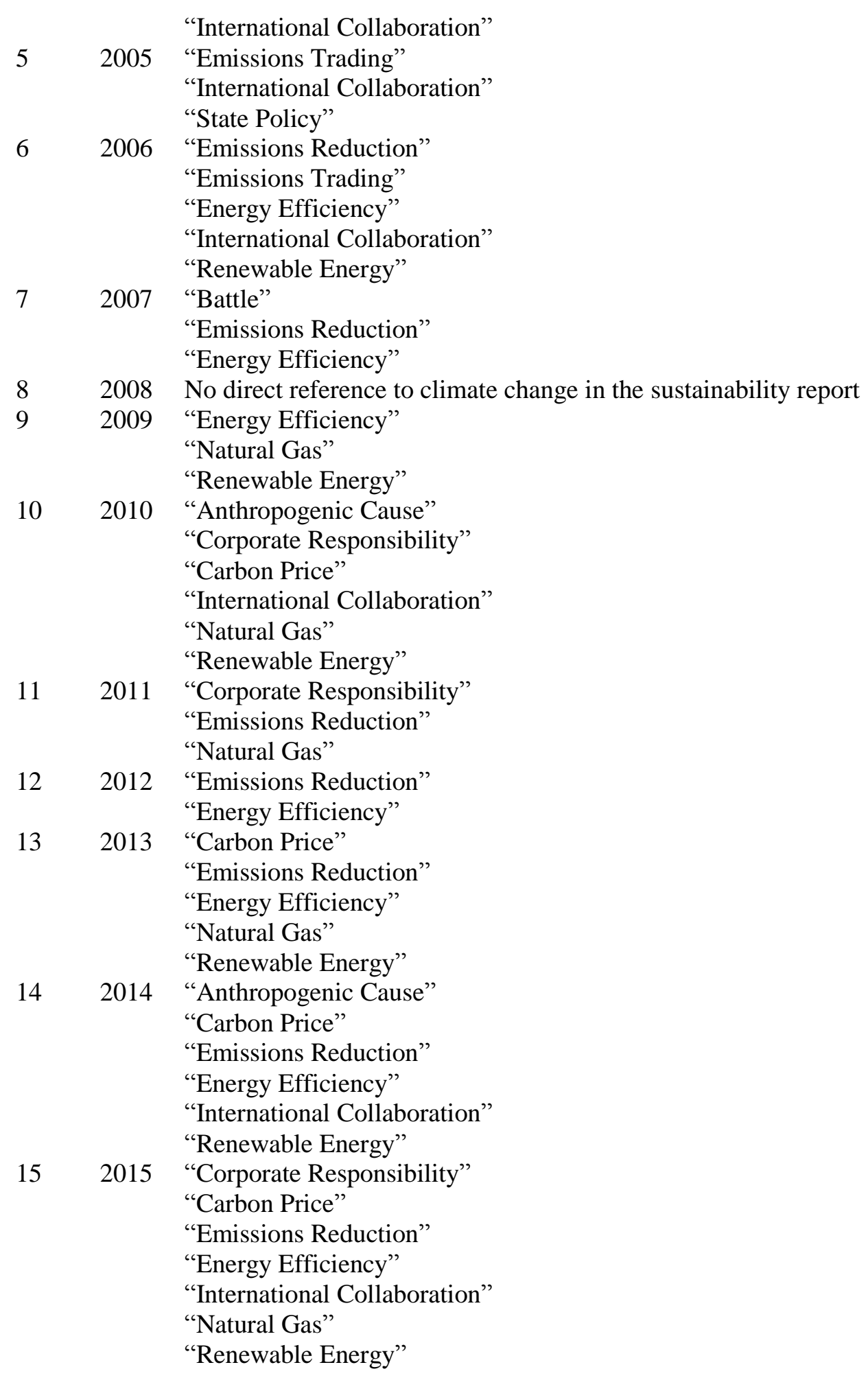

As previously mentioned in the introductory part of this article, international fossil fuel corporations tend to resort to "greenwashing" as a strategy of corporate image making. Statoil appears to state that the issue of climate change has been caused by human activities. The statement referring to anthropogenic climate change is construed by means of the frame "Anthropogenic Cause", which appears to be a recurrent feature of Statoil's corporate discourse. Statoil exhibits a sense of corporate responsibility by acknowledging its impact on climate and environment. Statoil's corporate responsibility can be broadly understood as the corporation's endeavour to maintain its positive public image and reputation (Benn, Dunphy, and Griffiths, 2014; Curran, 2017). Assuming that public image 
is an important notion to fossil fuel corporations, Statoil explicitly indicates its share of responsibility for climate change and offers a roadmap to mitigate its negative consequences as a part of a corporate discursive strategy to maintain a positive public image.

Typically, climate change mitigation is associated with sustainability. Similarly to BP and Shell, Statoil has introduced discursive practices that involve the concepts of responsibility and sustainability into its corporate discourse (Kapranov, forthcoming). Statoil's discourse addresses sustainable development in conjunction with the issues of climate change, waste management and renewable energy (Statoil, 2001). For instance, Statoil's discursive space in the 2015 Sustainability Report is characterized by the corporation's commitment to climate change mitigation. Statoil (2015) emphasizes a need for transparent reporting on measures to mitigate climate change, as seen in Excerpt (1):

(1) Our shareholders are increasingly asking for greater transparency about the measures we are taking to respond to climate risks and to ensure that our business model evolves in line with changing realities and expectations. In May 2015, our Annual General Meeting passed a shareholder resolution calling for greater disclosure around all aspects of how we are responding to climate change. (Statoil, 2015, p.10)

The frame "Corporate Responsibility" demonstrates Statoil's commitment to corporate responsibility and sustainable development, which is embedded into transparent and responsible reporting about climate change, e.g. "greater disclosure around all aspects of how we are responding to climate change" (Statoil, 2015, p.10). In conjunction with corporate responsibility for the issue of climate change, Statoil foregrounds the importance of its senior executives' awareness of climate change as a facet of corporate responsibility:

(2) To improve our executive leadership capabilities in relation to climate and energy, we launched the climate and energy leadership programme in 2011. Ten senior executives have been nominated to take part in the programme, which started in October 2011 and lasts for one year. Ten new senior executives will be nominated every six months. After completing the programme, participants are expected to actively invest into the company's ability to identify and respond to future uncertainties within their respective areas of responsibility. (Statoil, 2011, p.50)

The sustainability reports published in 2001, 2003, 2004, 2010 and 2014 indicate that Statoil as a responsible corporation acknowledges that climate change is anthropogenic and is associated with multiple negative consequences. The framing of climate change as "Anthropogenic Cause" appears to serve as Statoil's stance on the issue of climate change, corporate responsibility for its causes, and the further need for sustainable development as a means of climate change mitigation. Whilst the framing of climate change by Statoil by means of "Anthropogenic Cause" is not consistently used in all the sustainability reports, Statoil foregrounds this framing by placing it in the initial sections of the reports, e.g. in the 2004 Sustainability Report it is found as the opening sentence: "Climate change caused by human activity..." (Statoil, 2004, p.33). The text-initial position of this framing is reinforced in the 2014 Report by referring to the issue of climate change as "human-induced" and "manmade", as evident from Excerpt (3):

(3) Statoil acknowledges the scientific consensus on human-induced climate change, and supports the efforts of the United Nations and its member states to agree on and implement necessary climate measures to prevent dangerous manmade interference with the climate system. (Statoil, 2014, p.10)

It is stated in (3) that Statoil acknowledges the scientific consensus associated with the issue of climate change. It should be noted that the so-called consensus paper by Cook et al. was published in 2013. In the paper, Cook and the colleagues (2013) posit that a scientific consensus is needed in order to secure public support for climate change policy. It is interesting to observe that the notion of scientific consensus is explicitly mentioned by Statoil one year following Cook et al.'s (2013) publication. 
Statoil frames human-induced climate change by the frame "Battle". Judging from the data, the "dangerous manmade interference with the climate system" (Statoil, 2014, p.10) is treated by Statoil as a battle to be combatted, e.g. "We endorse the Kyoto protocol, which we see as the basis for global cooperation to combat climate change." (Statoil, 2001, p.55). The framing of climate change mitigation by means of the frame "Battle" is not frequent in the sustainability reports, being used twice, in the 2001 and 2007 reports, e.g.

(4) Our new climate policy - endorsed by the corporate executive committee in January 2008 takes account of the need to combat global climate change proactively... Carbon capture and storage are... a well-known example of measures which make a difference in the fight against global warming. (Statoil, 2007, p.26-27)

The results of the data analysis suggest that rather than regarding climate change mitigation as a metaphorical battle, Statoil prioritizes greenhouse emission reduction as a means of climate change mitigation. The frame "Emissions Reduction" was identified in the sustainability reports published in 2001-2004, 2006, 2007 and 2012-2015. Statoil acknowledges that emissions from the production and use of fossil fuels, e.g. Statoil-operated power generation, flaring and venting, contribute to the negative consequences of climate change (Statoil, 2012, p.34). This explicit acknowledgement is supported by the statement that Statoil participates in the reduction of global emissions of greenhouse gases (Statoil, 2002, p.21). Subsequently, Statoil frames greenhouse emission reduction by a set of measures including "removal and underground storage of carbon dioxide from produced gas, energy optimisation, improved efficiency in power generation..." (Statoil, 2001, p.57).

The frame "Emissions Reduction" appears to be associated with Statoil's international cooperation with both national and international bodies "to realise projects which reduce greenhouse gas emissions outside Norway" (Statoil, 2006, p.35). Additionally, the frame "Emissions Reduction" is related to scientific research involved in the reduction of greenhouse gases. In particular, Statoil demonstrates "a strong commitment to environmental and climate research aimed at identifying new solutions for reducing carbon emissions..." (Statoil, 2011, p.50). In this frame, there seems to be an emphasis on technological solutions to minimize the emissions, e.g. "...we are involved in several technology projects aimed at reducing greenhouse gases from our shipping activity. These projects focus on both new technical solutions and what type of energy carriers can be used in future" (Statoil, 2011, p.50). The framing of emission reductions by means of focusing on technical solutions is illustrated by Excerpt (5):

(5) We are among the companies with the lowest carbon dioxide emissions per unit of oil and gas produced. This has been achieved by developing and adopting new technical solutions which provide high energy efficiency and low greenhouse gas emissions. Results achieved with carbon dioxide are calculated by comparing actual emissions with the volume which we would have released if special measures had not been taken. (Statoil, 2003, p.19)

It is evident from (5) that emission reductions are carefully calculated by Statoil by "comparing actual emissions with the volume which we would have released if special measures had not been taken" (Statoil, 2003, p.19). In 2012, Statoil introduced a CO2 emissions reduction indicator into the framing of emission reductions to measure " $\mathrm{CO} 2$ reduction achieved through targeted projects implemented for Statoil-operated assets. The intention is that this indicator will be used in the future to measure progress towards our 2020 business segment-based carbon intensity targets..." (Statoil, 2012, p.33).

The sustainability reports data demonstrate that in addition to framing climate change discourse by means of "Emissions Reductions", Statoil employs the frame "Energy Efficiency". This frame is identified in the reports published in 2006, 2007, 2009 and in 2012-2015. In terms of energy efficiency, Statoil positions itself "among the industry leaders for high levels of efficiency and low emissions per unit of oil produced" (Statoil, 2007, p.26). Assuming leadership status, Statoil's aim is to "make our biggest contributions to energy efficiency by designing new facilities so that they consume as little energy as possible" (Statoil, 2006, p.30). Extending the vision of Statoil as a leader of energy efficiency on the fossil fuels market, the corporation "continued to focus on initiatives to improve energy efficiency in our operations, including implementation of energy efficiency plans for each of our installations..." 
(Statoil, 2012, p.33). It is implied in the sustainability reports that the concept of energy efficiency is regarded by Statoil as a significant means of emission reductions:

(6) ...the world's greenhouse emissions must be reduced. The scale of the challenge means that all options must be used. Energy efficiency is one important tool... our industrial response to the climate challenge is to focus on energy efficiency... (Statoil, 2009, p.3)

Whereas Statoil emphasizes the role of emission reductions by physically reducing their volume, the corporation offers another solution to emission reductions. According to Statoil, emission reductions can eventuate from emissions trading. The frame "Emissions Trading" is present in the sustainability reports published in 2001-2006, as seen in Excerpt (7):

(7) Statoil supports trading with credits obtained from reductions in other countries as a way for nations to comply with their obligations under the Kyoto protocol. We also support the implementation of domestic and regional emission trading schemes, provided these increase cost efficiency and do not reduce competitiveness in the industrial sector. We are currently preparing to take part in emission trading through our participation in the World Bank prototype carbon fund (PCF). (Statoil, 2006, p.57)

It should be noted that no such framing was identified in the reports published after 2006. It can be assumed that Statoil's emphasis on emissions trading between 2001 and 2006 is associated with the mechanisms specified in the Kyoto protocol (Statoil, 2002, p.21), since the reduction of emissions by Statoil "with the aid of the Kyoto mechanisms and emission trading occupies a key place in our collaboration with the International Emission Trading Association..." (Statoil, 2003, p.20). Presumably, another variable which facilitates the framing of climate change via the frame "Emissions Trading" involves the establishment of Statoil's emissions trading entity in 2005 in order to comply with both the Norwegian and the EU's emissions trading systems for carbon dioxide in 2005 (Statoil, 2006, p.31).

Whilst Statoil's framing of climate change narrative prior to 2006 is characterized by the presence of the frame "Emissions Trading", this framing is superseded by the introduction of the concept of the global price on carbon. The frame "Carbon Price" was identified in the 2010 and 2013-2015 sustainability reports, respectively. For instance, Statoil indicates that among numerous means of reducing greenhouse gases emissions, "the most efficient vehicle would be a sufficiently high global price on carbon. A global framework for carbon prices would create a level playing field for industry enterprises to reduce emissions" (Statoil, 2010, p.69). It is observed in the data that initially Statoil's frame "Carbon Price" is characterized by the discursive means of hedging, e.g. "...efficient vehicle would be a sufficiently high global price", and "A global framework for carbon prices would create...". However, in the more recent reports published in 2013 and 2014, this framing is marked by a clearly assertive tonality: "We actively advocate international measures that put a price on carbon which reflects the real impact of emissions" (Statoil, 2014, p.10). Identical assertiveness involving the global price on carbon is expressed in Excerpt (8):

(8) We advocate a global price on carbon reflecting the real impact of emissions, in order to stimulate technologies that can deliver energy with minimum carbon footprint. We work with peers and business organisations to convince policy makers that the EU ETS needs to urgently deliver a price signal that will stimulate fuel switching from coal to gas and investments in low carbon technologies. (Statoil, 2013, p.8)

Arguably, a possible reason why a global price on carbon has replaced the focus on an emissions trading scheme involves the shift in Statoil's framing of climate change. Paraphrasing Koteyko and the colleagues (2010), it could be assumed that the global price on carbon is employed "as an effective tool to communicate different approaches, framings, and attitudes related to the complex and urgent problem of climate change" (Koteyko, Thelwall, and Nerlich, 2010, p.49).

In (8), the need to "urgently deliver a price signal" (Statoil, 2013, p.8) is explained by Statoil's view of natural gas as a means of emissions reductions "that will stimulate fuel switching from coal to gas and investments in low carbon technologies" (ibid.). The results of the data analysis demonstrate that 
Statoil increasingly frames its climate change discourse by means of the frame "Natural Gas". First introduced in the 2001 report, the frame "Natural Gas" constitutes a recurrent theme in the 2009-2011, 2013 and 2015 sustainability reports. By framing natural gas as a potent tool for solving the issue of climate change, Statoil acknowledges its role as the second largest supplier of natural gas to Europe. According to Statoil, natural gas "will have an essential role to play in finding a solution to the climate challenge" (Statoil, 2009, p.3). The focus on the role of natural gas as a practical means of climate change mitigation is supported by Statoil's view "that delivering a reliable supply of natural gas is our greatest contribution to solving the energy and climate dilemma" (Statoil, 2011, p.49). This focus on natural gas is metaphorically compared by Statoil with a golden opportunity to reduce emissions, as seen in Excerpt (9):

(9) In 2012, we publicly shared our positions on climate change, available at Statoil.com. Our major contribution is the supply of clean, affordable and abundant natural gas. As the second largest supplier of natural gas to Europe, we provide energy that offers a golden opportunity to reduce emissions. Natural gas emits about 50\% less carbon dioxide than coal and can effect significant, immediate reductions in emissions when it replaces coal. (Statoil, 2013, p.8)

Concurrently with the significant role of natural gas as a means of climate change mitigation, the data point to Statoil's attention to renewables. The results of the data analysis reveal that the framing of renewables by means of the frame "Renewable Energy" is present in the 2002, 2003, 2006, 2009, 2010 and 2013-2015 sustainability reports. As posited by Statoil, "The development of renewable energy is important to us, and in this context our focus will be offshore wind and sustainable biofuels" (Statoil, 2009, p.3). Consequently, the frame "Renewable Energy" is comprised of Statoil's references to i) bioenergy, which "is playing a significant role in supplying heat in the Nordic energy market" (Statoil, 2002, p.23); ii) tidal power, which Statoil has contributed actively "to developing technology for generating renewable electricity from tidal currents" (Statoil, 2003, p.21); and iii) offshore wind as an area that "builds on our expertise in marine operations and managing large, complex offshore projects" (Statoil, 2013, p.14).

The frame "Renewable Energy" seems to be embedded into the frame "Corporate Responsibility". By blending the frames "Renewable Energy" and "Corporate Responsibility", Statoil portrays itself as an environmentally responsible corporation. The combination of these frames highlights Statoil's environmentally conscious image, which the corporation projects onto its customers. As a responsible and environmentally conscious corporation, Statoil encourages customers to buy biofuels to reduce fossil fuels emissions, thus indirectly contributing to the issue of climate change mitigation:

(10) We try to encourage our customers to use more environmentally responsible transport fuels by raising their awareness of the benefits of biofuels and new fuel additives. An increasing number of our customers wish to contribute to a more sustainable world by making reasonable, but considerate everyday choices. (Statoil, 2010, p.69)

In (10), the reference to "a more sustainable world" (Statoil, 2010, p.69) is indicative of Statoil's self-image as an international corporation which is involved in consumers' decision-making on the global energy market. Similarly to (10), Statoil's global involvement is foregrounded in the corporate narrative of climate change regarded by Statoil through the lens of international cooperation. The framing of the issue of climate change as the frame "International Collaboration" is evident from several sustainability reports, e.g. the 2002-2005, 2010 and 2014-15 reports. In particular, Statoil "believes that the greenhouse effect that creates global climate changes must be managed through binding international and global collaboration" (Statoil, 2005, p.42). Subsequently, the issue of climate change "must be dealt with through international collaboration. We actively support the Kyoto protocol and believe that the mechanisms defined in the protocol should be adopted to achieve the most cost-effective emission reductions" (Statoil, 2003, p.19).

The frame "International Collaboration" involves international cooperation associated with i) carbon capture and storage, e.g. "We have been collaborating well internationally for several years on carbon storage. Research institutes from countries all over the world are participating together with the supplies industry..." (Statoil, 2004, p.33), and ii) methane emissions, e.g. "...we sharpened out focus on 
collaborative efforts to address global methane emissions ... Together with GE, we have initiated a joint technology-focused programme to pursue industrial solutions designed to reduce the environmental impact of oil and gas production" (Statoil, 2014, p.10). In the latter quote, Statoil specifies its international collaboration by mentioning GE (General Electric), another major corporate actor. In this regard, it should be mentioned that Statoil frames its international collaboration efforts associated with climate change in a precise and concrete manner, referring to corporate, international and supranational actors, as seen in Excerpt (11):

(11) We collaborate with various partners to understand how climate change and climate policy and regulations will affect our business. In addition to our partners in fields and projects, we are working with several international partners to address the climate challenge. They include the United Nations, the World Bank, the World Business Council for Sustainable Development, the International Energy Agency, OECD, Oxford Institute, Ipieca, Xynteo and Cicero. In 2010, we have been an active member of the UN Secretary General's Advisory Group on Energy and Climate Change (AGECC), in which CEO Helge Lund has been directly involved. We are the only oil and gas company represented on the AGECC, which consists of more than 20 industry executives, UN representatives and experts from research organisations. (Statoil, 2010, p.80)

Excerpt (11) illustrates the importance which Statoil assigns to its collaboration with international actors, e.g. the UN, the World Bank etc. By framing its climate change activities by means of the frame "International Cooperation", Statoil's narrative foregrounds its unique role as a fossil fuel corporation, which is "the only oil and gas company represented on the AGECC, which consists of ... industry executives, UN representatives and experts..." (Statoil, 2010, p.80).

Whilst the frame "International Collaboration" is associated with a variety of international actors, Statoil appears to frame its climate change discourse as an issue relevant to domestic Norwegian stakeholders. The Norwegian government is one of these stakeholders. Hence, Statoil's framing of climate change discourse is executed by means of the frame "Government Policy", illustrated by Excerpt 12 below:

(12) The new Norwegian government that came into power in the autumn of 2005 has stressed the importance of capturing, storing and using carbon dioxide for IOR. The government has indicated that it may make a considerable contribution to such activities, both financially and by establishing state-owned companies that can capture carbon dioxide and supply it to fields for IOR application. On this basis, Statoil has stepped up further its commitment in order to clarify opportunities and financial prerequisites for implementing IOR through the use of carbon dioxide. (Statoil, 2005, p.43)

Arguably, the frame "Government Policy" serves a dual purpose of presenting i) the 2005 Norwegian government as a climate change concerned actor and ii) Statoil as a responsible and law-abiding actor that complies with the government's measures to address climate change and reinforces the previously undertaken obligations associated with climate change mitigation. Data analysis indicates that the frame "Government Policy" does not occur in the reports published after 2005.

\section{Conclusion}

The present article involves a qualitative study aimed at establishing how Statoil frames its climate change discourse in its annual sustainability reports. In total, 15 sustainability reports have been analysed for the presence of the frames associated with the issue of climate change. The results of the framing analysis demonstrate that Statoil frames its climate change discourse within the time period from 2001 until 2015 by the following frames: "Anthropogenic Cause", "Battle", "Corporate Responsibility", "Emissions Reduction", "Emissions Trading", "Energy Efficiency", "Carbon Price", "International Collaboration", "Natural Gas", "Renewable Energy" and "Government Policy".

The analysis of the data reveals that these frames are not equally distributed throughout the reports. Specifically, some framing can be considered one-off, e.g. the frame "Government Policy" was identified in the 2005 Sustainability Report only. There is a set of frames which are used in the 2000s and are not present in the 2010s sustainability reports. For instance, the frame "Emissions Trading" was 
identified in the reports prior to 2006, but this framing appears to be superseded by the introduction of the frame "Carbon Price", identified in the 2010 and 2013-2015 sustainability reports. However, there are several recurrent frames which are present in the majority of the recent reports, for instance, the frames i) "Energy Efficiency", which was identified in the reports published in 2006, 2007, 2009, and in 2012-2015, and ii) "Emissions Reduction", identified in the sustainability reports published in 20012004, 2006, 2007 and 2012-2015. Arguably, the changes in the distribution of these frames in diachrony could be explained by Statoil's affiliation with the Norwegian government as a partially state-run corporation. Statoil is legally obliged to abide by the international climate change treaties and protocols signed by Norway. Consequently, climate change legislature maps onto Statoil climate change discourse and causes changes in Statoil's framing of the issue of climate change.

The present findings have revealed a specific frame in Statoil's climate change discourse, which differentiates Statoil from other fossil fuel corporations. This frame is "Anthropogenic Cause", which is present in several sustainability reports. The frame "Anthropogenic Cause" is indicative of Statoil's awareness of human-induced climate change. It should be mentioned that this frame has not been identified in corporate discourse involving climate change by fossil fuel corporations in the US (Kapranov, 2017). In particular, Exxon has been reported to question the findings of climate scientists and to doubt the validity of scientific research involving greenhouse gases emissions (Kapranov, 2017). Whilst a contrastive study of Exxon's and Statoil's climate change discourse is not the focus of this article, it seems pertinent to mention that Exxon, unlike Statoil, is a private corporation. Presumably, as a private actor, it enjoys comparative leeway in terms of its climate change discourse (Kapranov, 2017). Hence, Exxon frames its climate change discourse by foregrounding such frames as "Risk", "Challenge", "Natural Gas" and "Costs" (Kapranov, 2017a). In contrast with Exxon, Statoil's discourse about climate change is explicit about the manmade causes of climate change. Statoil's awareness of human-induced climate change is embedded into the frame "Corporate Responsibility", which marks several of Statoil's sustainability reports. Previous scholarship indicates that the frame "Corporate Responsibility" is present in the climate change discourse of other fossil fuel corporations, e.g. BP and Shell (Kapranov, forthcoming). Similarly to Statoil, these corporate actors acknowledge their responsibility for climate change and introduce measures to mitigate its negative consequences. These findings suggest that Statoil's framing of climate change in its sustainability reports converges with that of European-based fossil fuel corporations and diverges from that of its North American counterparts. The differences in the framing of climate change discourse by Statoil and North American fossil fuel corporations seem to be a promising and topical avenue of future research, especially in the context of climate change action taken by Trump's administration.

\section{Acknowledgment}

I want to acknowledge the post-doctoral funding provided by the Norwegian Research Council (Norway) and the University of Bergen (Norway) within the framework of the LINGCLIM project (grant N 220654).

\section{References}

Benford, R. D. and Snow, D. A., 2000. Framing processes and social movements: An overview and assessment. Annual Review of Sociology, vol. 26, no.1, pp. 611-639.

Benn, S., Dunphy, D. and Griffiths, A., 2014. Organizational change for corporate sustainability. London/NY: Routledge.

Benjamin, D., Han-Hui, P. and Budescu, D., 2016. Climate change versus global warming: Who is susceptible to the framing of climate change? Environment and Behavior, vol. 49, no. 7, pp. 745770.

Berbes-Blazques, M., C. et al., 2017. Understanding climate change and resilience: assessing strengths and opportunities for adaptation in the Global South. Climatic Change, vol. 141, no. 2, pp. 227-241.

Chong, D. and Druckman, J. N., 2007. A theory of framing and opinion formation in competitive elite environments. Journal of Communication, vol. 57, no. 1, pp. 99-118.

Cook, J. et al., 2013. Quantifying the consensus on anthropogenic global warming in the scientific literature. Environmental Research Letters, vol. 8, no. 2, pp. 1-8. 
Cornelissen, J. P., Holt, R. and Zundel, M., 2011. The role of analogy and metaphor in the framing and legitimization of strategic change. Organization Studies, vol. 32, no. 12, pp. 1701-1716.

Cranmer, G. A., Bowman, N. D. and Goldman, Z. W., 2017. A preliminary study of racialized brawn and brain framing effects. Communication Research Reports, vol. 34, no. 1, pp. 78-83.

Curran, G., 2017. Social licence, corporate social responsibility and coal seam gas: framing the new political dynamics of contestation. Energy Policy, vol.101, pp. 427-435.

Dahl, T., 2017. Verbal and visual framing activity in climate change discourse. The role of language in the climate change debate, 13 , pp. 29-46.

Dahl, T., 2015. Contested science in the media: Linguistic traces of news writers' framing activity. Written Communication, vol. 32, no. 1, pp. 39-65.

De Vries, G., Terwell, B.W. and Ellemers, N., 2015. Perceptions of manipulation and judgements of illegitimacy: Pitfalls in the use of emphasis framing when communicating about $\mathrm{CO} 2$ capture and storage. Environmental Communication, vol. 10, no. 2, pp. 206-226.

Doyle, J., 2007. Picturing the clima(c)tic: Greenpeace and the representational politics of climate change communication. Science and Culture, vol. 16, no. 2, pp.129-150.

Entman, R. M., 1993. Framing: Toward clarification of a fractured paradigm. Journal of Communication, vol. 43, no. 4, pp. 51-58.

Fløttum, K. and Gjerstad, Ø., 2017. Narratives in climate change discourse. WIREs Climate Change, vol. 8, pp. 1-15.

Garcia, M.M., 2011. Perception is truth: How US newspapers framed the 'Go Green' conflict between BP and Greenpeace. Public Relations Review, vol. 37, pp. 57-59.

Gebara, M. F. et al., 2017. Framing REDD+ in the Brazilian national media: how discourses evolved amid global negotiation uncertainties. Climate Change, vol. 1, pp. 1-14.

Goffman, E., 1974. Frame analysis: An essay on the organization of experience. Harvard University Press.

Gonenc, H. and Scholtens, B., 2017. Environmental and financial performance of fossil fuel firms: a closer inspection of their interaction. Ecological Economics, vol. 132, pp. 307-328.

Graham, C., 2017. The future is not what it used to be: oil and gas strategies for a carbon-conscious world. The APPEA Journal, vol. 57, no. 2, pp. 459-461.

Hurlstone, M. J. et al., 2017. Cooperation studies of catastrophe avoidance: implications for climate negotiations. Climatic Change, vol.140, pp. 119-133.

Jaspal, R. and Nerlich, B., 2014. When climate science became climate politics: British media representations of climate change in 1988. Public Understanding of Science, vol. 23, no. 2, pp. $122-$ 141.

Kapranov, O., forthcoming. Shell's image of climate change and its representations in the British financial press. In W. Giordano (ed.). Discourse, communication and the enterprise: Where Business meets language. Cambridge Scholar Publishing.

Kapranov, O., 2017. Conceptual metaphors associated with climate change in corporate reports in the fossil fuels market. Two perspectives from the United States and Australia. In: K. Fløttum (ed.) The role of language in the climate change debate. London/NY: Taylor \& Francis, pp. 102-122.

Kapranov, O., 2017a. British Petroleum's corporate discourse involving climate change before and after the Deepwater Horizon oil spill: A cognitive linguistic account. Selected Papers on Theoretical and Applied Linguistics, vol. 22, pp. 211-223

Kapranov, O., 2016. Corpus analysis of discourse markers in corporate reports involving climate change. EPiC Series in Language and Linguistics, vol.1, pp. 216-227.

Kapranov, O., 2015. Do international corporations speak in one voice on the issue of global climate change: The case of British Petroleum and The Royal Dutch Shell Group. In C. Cem and K. Papaja, eds. Global perspectives on social sciences and humanities. Theory and practice Warsaw: LiF.

Koteyko, N., Thelwall, M. and Nerlich, B., 2010. From carbon markets to carbon morality: Creative compounds as framing devices in online discourses on climate change mitigation. Science Communication, vol. 32, no. 1, pp. 25-54.

Kropp, C. and Türk, J., 2017. Bringing climate change down to earth: Climate change governance from the bottom up. In: A. Esguerra et al., eds. Sustainability politics and limited statehood. Palgrave Macmillan, Cham., pp.179-210. 
Lakoff, G., 2006. The contemporary theory of metaphor. In D. Geeraerts, ed. Cognitive linguistics: Basic readings. Amsterdam: Walter de Gruyter, pp. 185-237.

Levin, I. P., Schneider, S. L. and Gaeth, G. J., 1998. All frames are not created equal: A typology and critical analysis of framing effects. Organizational Behaviour and Human Decision Processes, vol.76, no. 2, pp. 149-188.

Livesey, S. M., 2002. Global warming wars: Rhetorical and discourse analytic approaches to Exxonmobil's corporate public discourse. Journal of Business Communication, vol. 39, pp. 117-146.

Lopez Maestre, M.D., 2000. The business of cognitive stylistics: A survey of conceptual metaphors in business English. Atlantis, vol. 22, no. 1, pp. 47-69.

Lyon, T. P. and Montgomery, W., 2015. The means and end of greenwash. Organization and Environment, vol. 28, no. 2, pp. 223-249.

Marhsall, G., 2007. Carbon detox: Your step-by-step guide to getting real about climate change. Hachette UK.

Matejek, S. and Gössling, T., 2014. Beyond legitimacy: A case study of BP's 'green lashing'. Journal of Business Ethics, vol. 120, no. 4, pp. 571-584.

Matthes, J. and Kohring, M., 2008. The content analysis of media frames: Toward improving reliability and validity. Journal of Communication, vol. 58, no. 2, pp. 258-279.

Myers, T. A. et al., 2012. A public health frame arouses hopeful emotions about climate change. A Letter. Climatic Change, vol. 113, pp. 1105-1112.

Nerlich, B. and Jaspal, R., 2013. UK media representations of carbon capture and storage: actors, frames and metaphors. Metaphor and the Social World, vol. 3, no.1, pp.35-53.

Nilsen, T., 2017. Innovation from the inside out: Contrasting fossil and renewable energy pathways at Statoil. Energy Research \& Social Science, vol. 28, pp. 50-57.

Nisbet, M. C., 2009. Communicating climate change: Why frames matter for public engagement. Environment: Science and Policy for Sustainable Development, vol. 51, no. 2, pp.12-23.

Scanlan, S. J., 2017. Framing fracking: scale-shifting and greenwashing risk in the oil and gas industry. Local Environment, vol. 22, no.11, pp. 1311-1337.

Schmid-Petri, H. and Arlt, D., 2016. Constructing an illusion of scientific uncertainty? Framing climate change in German and British print media. Communications, vol. 41, no.3, pp.265-289.

Shehata, A. and Hopmann, D. N., 2012. Framing climate change. Journalism Studies, vol. 13, no. 2, pp. 175-192.

Spence, A. and Pidgeon, N., 2010. Framing and communicating climate change: The effects of distance and outcome. Global Environmental Change, vol. 20, pp.656-667.

Starbird, K. et al., 2015. Social media, public participation, and the 2010 BP Deepwater Horizon oil spill. Human and Ecological Risk Assessment: An International Journal, vol. 21, no. 3, pp. 605-630.

Statoil, 2001. Sustainability Report. [Accessed 1 February 2017]. Available at: https://www.statoil.com/content/dam/statoil/documents/sustainabilityreports/Sustainability_report_2001.pdf

Statoil, 2002. Sustainability Report. [Accessed 1 February https://www.statoil.com/content/dam/statoil/documents/sustainabilityreports/Sustainability_report_2002.pdf

Statoil, 2003. Sustainability Report. [Accessed 1 February https://www.statoil.com/content/dam/statoil/documents/sustainabilityreports/Sustainable_report_2003.pdf

Statoil, 2004. Sustainability Report. [Accessed 1 February https://www.statoil.com/content/dam/statoil/documents/sustainabilityreports/Sustainable_report_2004.pdf

Statoil, 2005. Sustainability Report. [Accessed 1 February https://www.statoil.com/content/dam/statoil/documents/sustainabilityreports/Sustainable_report_2005.pdf

Statoil, 2006. Sustainability Report. [Accessed 1 February https://www.statoil.com/content/dam/statoil/documents/sustainabilityreports/Sustainability_report_2006.pdf

2017]. Available at:

2017]. Available at:

2017]. Available at:

2017]. Available at:

2017]. Available at: 
Statoil, 2007. Sustainability Report. [Accessed 1 February 2017]. Available at: https://www.statoil.com/content/dam/statoil/documents/sustainabilityreports/Sustainability\%202007.pdf

Statoil, 2008. Sustainability Report. [Accessed 1 February 2017]. Available at: https://www.statoil.com/content/dam/statoil/documents/sustainabilityreports/Key_sustainability_performance_data_2008.pdf

Statoil, 2009. Sustainability Report. [Accessed 1 February 2017]. Available at: https://www.statoil.com/content/dam/statoil/documents/sustainabilityreports/Sustainability\%20report\%202009.pdf

Statoil, 2010. Sustainability Report. [Accessed 1 February 2017]. Available at: https://www.statoil.com/content/dam/statoil/documents/sustainabilityreports/Sustainability\%20report\%202010.pdf

Statoil, 2011. Sustainability Report. [Accessed 1 February https://www.statoil.com/content/dam/statoil/documents/sustainabilityreports/Sustainability\%20report\%202011.pdf

Statoil, 2012. Sustainability Report. [Accessed 1 February 2017]. Available at: https://www.statoil.com/content/dam/statoil/documents/sustainabilityreports/Sustainability_report2012.pdf

Statoil, 2013. Sustainability Report. [Accessed 1 February 2017]. Available at: https://www.statoil.com/content/dam/statoil/documents/sustainabilityreports/SustainabilityReport.pdf

Statoil, 2014. Sustainability Report. [Accessed 1 February 2017].Available at: https://www.statoil.com/content/dam/statoil/documents/sustainabilityreports/Sustainability_report_2014.pdf

Statoil, 2015. Sustainability Report. [Accessed 1 February 2017]. Available at: https://www.statoil.com/content/dam/statoil/documents/sustainability-reports/statoil-sustainabilityreport-2015.pdf

Swain, K. A., 2017. Mass Media Roles in Climate Change Mitigation. In W.-Y. Chen et al. (eds.), Handbook of Climate Change Mitigation and Adaptation (pp.169-208), DOI 10.1007/978-3-31914409-2_6.

Trenberth, K. E., 2012. Framing the way to relate climate extremes to climate change. Climatic Change, vol. 115 , pp. 283-290.

Tynkkynen, N., 2010. A great ecological power in global climate policy? Framing climate change as a policy problem in Russian public discussion. Environmental Politics, vol. 19, no. 2, pp. 179-195.

\section{Sources}

https://www.statoil.com/en/how-and-why/sustainability/sustainability-reports.html 